\title{
Iron in intracellular infection: to provide or to deprive?
}

\author{
Sandro Silva-Gomes ${ }^{1,2 *+}$, Sílvia Vale-Costa ${ }^{1,2 *+}$, Rui Appelberg ${ }^{1,2 *}$ and Maria S. Gomes ${ }^{1,2 *}$ \\ 1 Infection and Immunity Unit, Instituto de Biologia Molecular e Celular, Universidade do Porto, Porto, Portugal \\ ${ }^{2}$ Department of Molecular Biology, Instituto de Ciências Biomédicas Abel Salazar, Universidade do Porto, Porto, Portugal
}

\section{Edited by:}

Mathieu F. Cellier, Institut National de la Recherche Scientifique,

Canada

\section{Reviewed by:}

Geneviève Milon, Institut Pasteur, France

Michael Niederweis, University of Alabama at Birmingham, USA

\section{*Correspondence:}

Sandro Silva-Gomes, Sílvia Vale-Costa, Rui Appelberg and Maria

S. Gomes, Infection and Immunity

Unit, Instituto de Biologia Molecular e Celular, Universidade do Porto,

Rua do Campo Alegre 823,

4150-180 Porto, Portugal

e-mail: sandro@ibmc.up.pt;

svcosta@ibmc.up.pt;

rappelb@ibmc.up.pt;

sgomes@ibmc.up.pt

${ }^{\dagger}$ These authors have contributed

equally to this work.

\section{IRON IN BIOLOGIC SYSTEMS AND INFECTION PROCESSES}

Transition metals are elements that have an incomplete inner electron shell and can easily shift between different oxidation states. Cells took advantage of this property and included transition metals into proteins, gaining catalytic potential and protein stability. The function of transition metals in enzymatic catalysis can be divided into two groups, depending upon the metal acting as a redox center or not. Of the redox active metals, iron is the most prevalent, followed by copper and molybdenum, while zinc is the most common non-redox transition metal (Andreini et al., 2008). Iron is found in an unparalleled variety of sites and cofactors, such as haem groups and iron-sulphur clusters, and is involved in processes such as oxygen sensing and transport, energy metabolism and nucleic acid synthesis. The predominance of iron is presumably due to the large availability of water soluble ferrous iron during prebiotic times, before the rise of atmospheric oxygen levels caused by photosynthesis resulted in the precipitation of insoluble iron (III) (Crichton and Pierre, 2001). As a result, almost all living organisms from archaea to eukaryotes require iron in their metabolism. Borrelia burgdorferi is unique among pathogens in that it bypassed iron dependence by substituting zinc or manganese for iron in its metalloproteins (Posey and Gherardini, 2000; Nguyen et al., 2007).

Abbreviations: ACD, anaemia of chronic disease; $\beta 2 \mathrm{~m}$, beta-2-microglobulin; DFO, desferrioxamine; $\mathrm{HH}$, hereditary hemochromatosis; Lcn-2, Lipocalin 2; MHC-I, major histocompatibility complex class I; NO, nitric oxide; NOS2, nitric oxide synthase 2; ROS, reactive oxygen species.

\section{IRON METABOLISM IN THE HOST}

Vertebrates have evolved a complex network of proteins to acquire, transport and store iron, while maintaining free iron concentration at very low levels (reviewed in Kaplan and Ward, 2013). In mammals there is no regulated excretion of iron and the replenishment of losses from desquamation and minor bleeding, which account for the loss of less than $0.05 \%$ of body iron per day, occurs at the level of intestinal absorption. Dietary iron, either inorganic or bound to haem, is absorbed at the brush border of enterocytes lining the proximal portion of the duodenum (Andrews and Schmidt, 2007). Iron is transported as ferrous iron into circulation through ferroportin, the only cellular iron exporter. Transferrin is the physiological carrier of iron in plasma, binding two atoms of ferric iron. In humans, the normal saturation of transferrin is only $20-40 \%$ (Ganz and Nemeth, 2012b). Iron-loaded transferrin binds with high affinity to the transferrin receptor (TFR)-1, ubiquitously expressed at cell surfaces, and is internalized by clathrin-dependent endocytosis. Iron is then released intracellularly and becomes part of the labile iron pool (Correnti and Strong, 2012). Iron that is not needed for immediate use or export is stored in ferritin. In vertebrates, cytosolic ferritin is formed by the spontaneous assembly of 24 subunits of Heavy (H) and Light (L) chains, resulting in a hollow shell capable of accommodating up to 4500 iron atoms in an inert, non-toxic form (Harrison and Arosio, 1996). Erythropoiesis is the most avid consumer of iron in the mammal organism. Approximately $60-70 \%$ of the human adult body iron is bound within haemoglobin $(\sim 2.5 \mathrm{~g})$. With the erythrocyte lifespan of 120 days, the reutilization of iron recycled from 
senescent cells accounts for most of the iron flux (Ganz and Nemeth, 2012b). The hormone hepcidin is regarded as the central regulator of systemic iron homeostasis. Hepcidin is a 25 amino acid peptide that is mainly produced by hepatocytes. It binds to the iron exporter ferroportin, causing its internalization and degradation. Consequently, it reduces the absorption of dietary iron by enterocytes and the release of iron from intracellular stores (Ganz and Nemeth, 2012a).

As described, macrophages play a central role in regulating iron metabolism since they recycle haem iron and regulate its storage. However, since macrophages respond to other environmental cues such as signals from the immune system, they may undergo major and distinct physiological adaptations in different settings namely those that are triggered by infection. For example, it is known that classic activation of macrophages (M1 macrophages) e.g., by gamma interferon together with microbial molecules acting as Toll-like receptor ligands modulates a different program of iron handling as compared to the alternative activation (M2 macrophages) induced by cytokines such as interleukin (IL)-4 and IL-13 induced in certain types of infection or by cues from tissues in steady-state conditions (Recalcati et al., 2012). The ensuing consequences at the systemic level are distinct as classic activation promotes the sequestration of iron leading to systemic lowering of its availability whereas alternative activation, by promoting export of the metal by macrophages would lead to the opposite systemic effects.

\section{TRANSITION METALS DURING INFECTION}

Successful colonization of a host by pathogens requires that these must gain access to the required amounts of transition metals. Vertebrate hosts exploit this requirement by sequestering these elements (Figure 1A). Iron withholding is the most wellstudied example of metal deprivation. A complex network of host proteins renders this valuable nutrient largely inaccessible to pathogens, a concept usually known as nutritional immunity (Appelberg, 2006a; Hood and Skaar, 2012). However, recent evidences suggest that this mechanism is also used to sequester other transition metals, including manganese and zinc (Kehl-Fie and Skaar, 2010). The strict requirement for transition metals is due to their involvement in numerous processes ranging from microbial metabolism to accessory virulence factor function. Hence, without the required concentration of these nutrients, the invading agent is unable to proliferate and cause disease (Kehl-Fie and Skaar, 2010).

The host can capitalize on the toxicity of transition metals and increase their concentration in the compartment where pathogens proliferate (Figure 1B). By this mechanism, transition metals can potentiate pathogen killing together with the respiratory burst in phagocytes. The moderately reactive superoxide radical is rapidly reduced to hydrogen peroxide, either spontaneously or enzymatically. In turn, hydrogen peroxide may give rise to the highly reactive and short-lived hydroxyl radicals in the Fenton reaction, by reacting with a reduced transition metal, such as $\mathrm{Fe}(\mathrm{II})$ or $\mathrm{Cu}(\mathrm{I})$ (Galaris and Pantopoulos, 2008; Hodgkinson and Petris, 2012), resulting in oxidative damage to the pathogen. The toxicity of copper against $M$. tuberculosis has been reported (Wolschendorf et al., 2011) and a copper-transporting ATPase

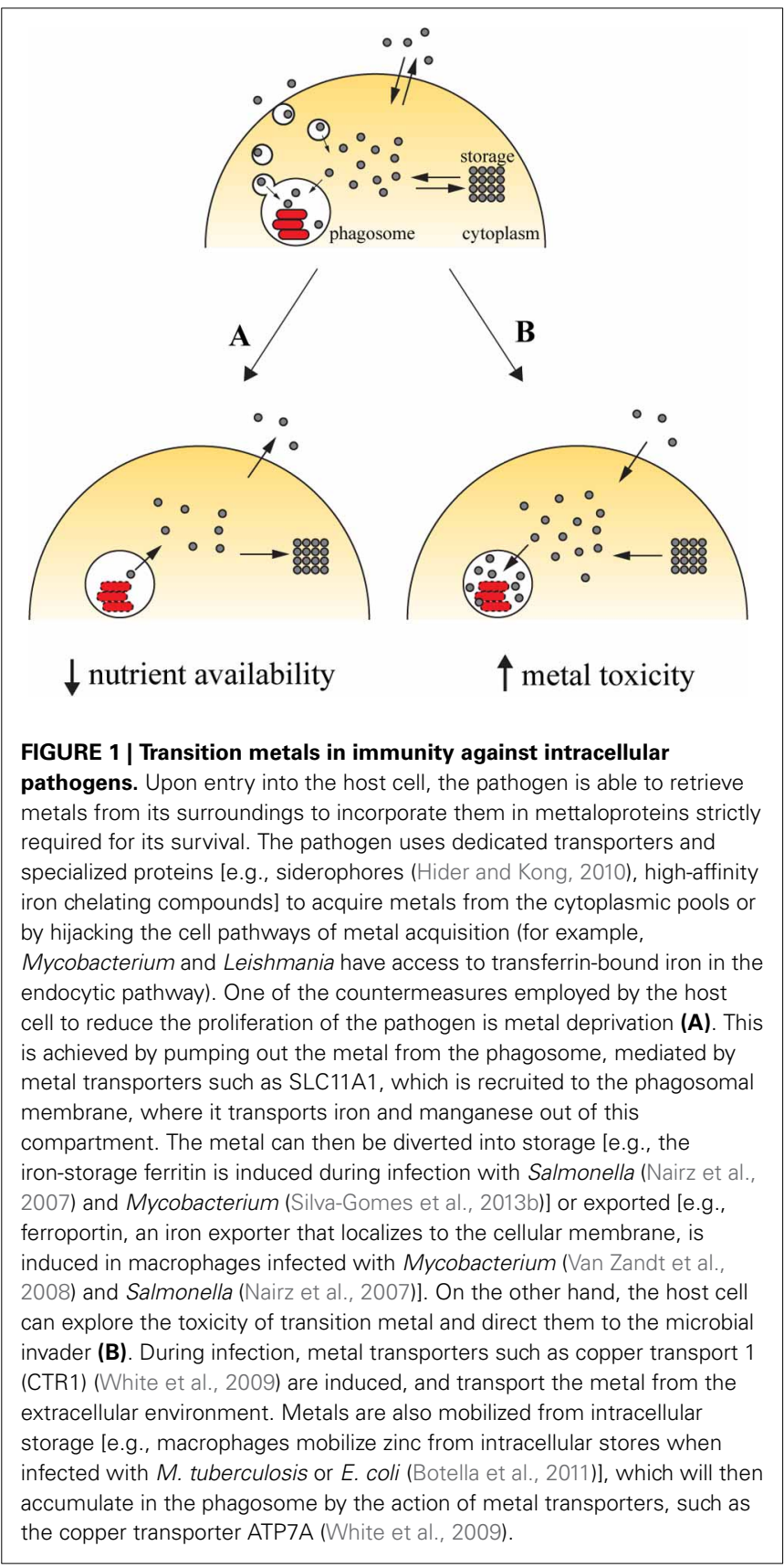

has been identified in macrophages (White et al., 2009). Other mechanisms of metal intoxication independent of oxidative stress have also been proposed. For example, it was suggested that metal cofactor replacement may mediate copper toxicity against bacteria (Rowland and Niederweis, 2012) and that perturbation of a defined ratio of transition metals is detrimental to bacterial physiology, which may underlie zinc and manganese toxicity (Botella et al., 2011; Hood and Skaar, 2012).

This review focuses on the effect of availability of iron, the most abundant transition metal in the vertebrate host, during infection with two intracellular pathogens, Mycobacterium and Leishmania. 


\section{IRON METABOLISM IN Mycobacterium INFECTION}

Tuberculosis remains the most important bacterial infection worldwide. It is estimated that one third of the world population is infected with M. tuberculosis. However, in $90 \%$ of the cases immunity is able to prevent disease, leading in the majority of cases to latent infection. The advent of the AIDS epidemic and the introduction of immunosuppressive therapies dramatically increased the number of people at risk of infection not only with $M$. tuberculosis but also with other Mycobacterium species that otherwise would not cause disease. This is the case of Mycobacterium avium, a Non Tuberculous Mycobacteria (NTM). Whereas $M$. tuberculosis is a primary pathogen, M. avium is seldom identified as one. The two mycobacterial species differ in that opportunistic infection by M. avium occurs in advanced stages of AIDS when blood CD4 ${ }^{+}$T cell counts are lower than 50 per $\mathrm{mm} 3$, whereas infection of AIDS patients with M. tuberculosis is not limited to such late stages of the disease. M. tuberculosis has no known reservoir other than humans. The bacteria are almost exclusively transmitted by aerosolized droplets, generated by the cough or sneeze of a person with $M$. tuberculosis lung infection and are inhaled by an uninfected person. In contrast, $M$. avium does not seem to be transmitted between hosts and infection occurs usually through tap water. Although mycobacteria can infect several cell types (e.g., epithelial cells, eosinophils, neutrophils and dendritic cells) the macrophage has long been established as the central cell during the infection, being the primary player of cellular immunity as well as the main site of bacterial replication. Despite the differences that make $M$. tuberculosis a highly successful pathogen and $M$. avium an opportunistic infectious agent that mostly affects patients with compromised immunity, studies in the mouse model showed that immune response to both mycobacteria is similar, namely regarding the pivotal roles of $\mathrm{CD}^{+} \mathrm{T}$ cells, macrophages, and the IL12-IFN $\gamma$ cytokine axis. This is also the case of iron availability, as it will be discussed below.

For a review regarding pathogenesis of infection with $M$. tuberculosis and M. avium we refer the readers to (Cooper, 2009) and (Appelberg, 2006b), respectively.

\section{HOST IRON STATE: EVIDENCES FROM HUMAN STUDIES}

Iron availability can be a determinant factor during infections with mycobacteria. In the nineteenth century, Armand Trousseau, a French physician, already documented the dangers of giving iron to patients suffering from tuberculosis. He observed that although tuberculosis patients developed some degree of anaemia, iron supplementation in their diet resulted in a poorer outcome than those patients who did not receive additional iron (Trousseau, 1872). Contemporary studies have corroborated this link between iron and tuberculosis. In 1996, Gordeuk et al. reanalyzed an autopsy study performed in South Africa in the 1920s, and found a relationship between death from tuberculosis and hepatic and splenic iron overload, notably with increased iron deposition in the mononuclear macrophage system (Gordeuk et al., 1996). Epidemiological studies in rural Zimbabwe have also shown a correlation between iron overload induced by dietary intake of iron (although genetic predisposition could also be a factor), and the risk of active pulmonary tuberculosis (Gangaidzo et al., 2001). Finally, a recent study has shown iron redistribution to macrophages in HIV infected patients to be a risk factor for the development of tuberculosis (McDermid et al., 2013).

Owing to the strict regulation of intestinal absorption, iron overload of mammalian organisms is rare. However, certain genetic diseases can lead to iron overload, such as hereditary hemochromatosis $(\mathrm{HH})$, the most common inherited single gene disorder in people of Northern and Western Europe. This disease is most often associated with mutations in a molecule, HFE, homologous to class I major histocompatibility complex (MHC) alpha chains. These patients spontaneously develop hepatic iron overload, with iron accumulation in hepatocytes but not in macrophages. Given the reduced capacity of the macrophage to retain iron, human macrophages from $\mathrm{HH}$ patients where shown to be less permissive to $M$. tuberculosis growth (Olakanmi et al., 2007). However, whether this is true at an all-organism level is not known, as epidemiologic data from the incidence of tuberculosis in $\mathrm{HH}$ patients are not available. Furthermore, results from mouse models of $\mathrm{HH}$ indicated that the overall tissue iron overload contributes to susceptibility to mycobacteria (discussed below).

\section{HOST IRON STATE: EVIDENCES FROM THE MOUSE MODEL}

For the most part, the findings in humans described above have been very effectively reproduced in the mouse model of experimental infections with mycobacteria.

Our group has shown that an iron poor diet led to a reduced proliferation of M. avium in mice (Gomes et al., 1999a), while the parenteral administration of iron-dextran led to an increased proliferation of the bacilli (Gomes and Appelberg, 1998; Gomes et al., 2001). Likewise, others have shown that either the parenteral overload of iron in the form of polymaltose ferric hydroxide (Lounis et al., 1999, 2001) (Lounis et al., 2003) or the administration of iron citrate through the drinking water (Schaible et al., 2002) rendered the mice more susceptible to experimental infection with M. tuberculosis.

Mice deficient in HFE or in the HFE-binding protein beta2-microglobulin $\left(\beta 2 \mathrm{~m}^{-/-}\right)$spontaneously develop hepatic iron overload, similar to $\mathrm{HH}$ patients (De Sousa et al., 1994; Zhou et al., 1998). $\beta 2 \mathrm{~m}^{-/-}$mice are known for a long time to be more susceptible to $M$. tuberculosis, an effect initially attributed to a lack of major histocompatibility complex class I (MHC-I) restricted cells (Flynn et al., 1992). However, MHC-I-KO animals are less susceptible to $M$. tuberculosis than $\beta 2 \mathrm{~m}^{-/-}$mice (Rolph et al., 2001; Schaible et al., 2002). Schaible et al. have shown that correcting the iron overload in these mice, through the administration of lactoferrin, reduced their mycobacterial loads to levels comparable to MHC-I-KO animals, proving that iron availability is the major factor accounting for the increased susceptibility of $\beta 2 \mathrm{~m}^{-/-}$mice to experimental tuberculosis (Schaible et al., 2002). In our group, we also found that the increased accumulation of iron in $\beta 2 \mathrm{~m}^{-/-}$mice is associated with an increased susceptibility to M. avium experimental infection (Gomes-Pereira et al., 2008). Furthermore, we showed a similar effect in $\mathrm{HFE}^{-/-}$mice (Gomes-Pereira et al., 2008). Interestingly, although these models of iron overload tend to accumulate iron in hepatocytes and not 
in macrophages, we observed that during infection iron accumulates in macrophages within granulomas (Gomes-Pereira et al., 2008).

\section{THE FIGHT FOR IRON}

In order to successfully establish an infection, mycobacteria must gain access to iron and have therefore evolved strategies to acquire iron from the host. Mycobacteria are able to block phagosomal maturation, replicating in an intracellular compartment with access to iron-loaded transferrin (Clemens and Horwitz, 1996; Halaas et al., 2010). Interestingly, the ability of M. avium to prevent phagosome maturation was shown to be dependent on its capacity to acquire iron (Kelley and Schorey, 2003). In addition to transferrin, M. tuberculosis was also shown to be able to acquire iron from lactoferrin (Olakanmi et al., 2004) and from the macrophage cytoplasmic iron pools (Olakanmi et al., 2002). Furthermore, M. tuberculosis can use haem as an iron source (Jones and Niederweis, 2011; Tullius et al., 2011; Nambu et al., 2013). In line with the notion that access to iron is a requisite to cause a persistent infection, it was reported, using $\mathrm{X}$ ray microscopy, that iron concentration increased over time in the phagosomes of macrophages infected with M. avium or $M$. tuberculosis, while it decreased in those infected with the nonpathogenic M. smegmatis (Wagner et al., 2005). Several bacteria are able to produce siderophores, low molecular weight molecules with high affinity for iron. Pathogenic mycobacteria, such as $M$. tuberculosis and M. avium, synthetize siderophores that remain associated to the cell wall, termed mycobactins, and others that are secreted, named carboxymycobactins (Ratledge, 2004). These siderophores are able to remove iron from host iron-binding proteins, such as transferrin and lactoferrin (Gobin and Horwitz, 1996). In M. tuberculosis a gene cluster that encompasses 10 genes, designated mbtA-J, encodes the machinery responsible for siderophore biogenesis (Quadri et al., 1998). mbtB (De Voss et al., 2000), mbtD (Jones and Niederweis, 2011), and mbtE (Reddy et al., 2013) mutants show restricted growth in iron-deficient medium and in macrophages, suggesting that siderophore synthesis is required for $M$. tuberculosis virulence. Indeed, guinea pigs infected with the $m t b E$ mutant exhibited reduced bacillary load in comparison with animals infected with the parental strain (Reddy et al., 2013). However, these latter data should be confirmed since this study showed that the mutant strain induced the same amount of moderate pathology in the lung as the wild type strain despite its virtually complete elimination by 4 weeks of infection. Whether that was due to the high inoculum used and the persistence of inflammatory material from the mycobacteria or to an underestimation of the bacterial loads given the difficulties in growing the mutant strain in vitro is unclear. Noteworthy, whereas pathology subsequently exacerbated in the hosts infected with the wild type strain, it did not in animals infected with the mutant strain. In addition to the synthesis of siderophores, proteins involved in their import or export are also critical for virulence. IrtAB, a transporter of iron-loaded carboxymycobactin, is required for the replication of $M$. tuberculosis in macrophages and in vivo in a mouse model of aerosol infection (Rodriguez and Smith, 2006). A siderophore export system was recently identified in M. tuberculosis, involving the proteins MmpS4 and
Mmsp5 (Wells et al., 2013). Deletion of both mmpS4 and mmpS5 drastically decreases synthesis and secretion of siderophores and notably reduces $M$. tuberculosis virulence in mice (Wells et al., 2013).

The essentiality of iron acquisition systems for mycobacterial survival has led to the suggestion that this pathway could constitute a new drug target in anti-mycobacteria drug development (Appelberg, 2006a; Meyer, 2006). In fact, several compounds with the capacity to interfere with siderophore synthesis and/or function were shown to have strong inhibitory activity against M. tuberculosis (Ferreras et al., 2005, 2011). It should be noted that although some compounds that interfere with siderophore synthesis showed promising results in axenic cultures of M. tuberculosis (Ferreras et al., 2005), their effect in a mouse model of $M$. tuberculosis infection is very limited (Lun et al., 2013). These observations may indicate that (1) mycobacteria have access in vivo to others forms of iron independent of siderophore acquisition [e.g., haem iron (Jones and Niederweis, 2011)] or (2) the compound is not reaching the cells harboring mycobacteria. Alternative possible targets for new drug development may instead include the siderophore transport systems. We have also shown that the addition of iron chelators to $M$. avium cultures, either in axenic culture, in macrophage cultures, or in vivo led to significant decreases in mycobacterial growth (Gomes et al., 1999a; Fernandes et al., 2010). Furthermore, we have developed new molecules based on the 3-hydroxy-4pyridinone iron chelating moiety, in which the inclusion of a rhodamine residue improved anti-mycobacterial activity, presumably through improved intracellular distribution and targeting for the mycobacteria-containing phagosome (Fernandes et al., 2010; Nunes et al., 2010; Moniz et al., 2013).

During an infection, the host uses several mechanisms to withhold iron access from pathogens. Anaemia often develops during acute or chronic infections, which is known as anaemia of chronic disease (ACD), and is thought to represent a mechanism to limit iron availability to the invading microorganisms (Weiss, 2009). ACD, the second most common type of anaemia (after anaemia of iron-deficiency) is characterized by hypoferremia (low serum iron) and increased iron retention within the mononuclear phagocyte system (Roy, 2010). Anaemia was described in the mouse model of infection with M. avium (Rodrigues et al., 2011) and M. bovis BCG (Marchal and Milon, 1981), and epidemiologic studies showed that tuberculosis is frequently associated with anaemia (Lee et al., 2006; Sahiratmadja et al., 2007). One of the putative links between immunity and the anaemia is hepcidin, a peptide that regulates iron homeostasis by mediating the degradation of ferroportin, an iron exporter protein. In vitro, infection of macrophages with $M$. avium and M. tuberculosis induce the hepcidin mRNA expression (Sow et al., 2007). However, using a microarray platform to analyse the iron-related genes regulated by M. avium infection, we did not find hepcidin to be induced in the liver (Rodrigues et al., 2011), questioning the role of hepcidin in the development of anaemia during mycobacterial infections. Nevertheless, hepcidin produced by infected macrophages may have a local effect, rather than a major role in the systemic iron regulation. Indeed, Sow et al. (2007) showed that hepcidin localizes to the mycobacteria-containing phagosomes and possesses 
direct antimicrobial activity against $M$. tuberculosis, causing structural damage to the mycobacteria. How anaemia develops in the context of mycobacterial infection remains to be determined. Anaemia independent of the expression of hepcidin has been observed in other situations, namely after LPS administration to TIR domain-containing adaptor protein (TRIF)-deficient mice (Layoun et al., 2012) and Hepcidin ${ }^{+/-}$mice (Deschemin and Vaulont, 2013), in a murine model of protracted peritonitis (Schubert et al., 2012) and notably following TNF administration to mice (Laftah et al., 2006).

There is experimental evidence that some degree of haemolysis and release of free haem may occur during severe infection (Larsen et al., 2010). Free haem contributes to an increased susceptibility to mycobacterial infection, most likely involving mechanisms that differ from those associated to other forms of iron, and haem-oxygenase-1, the enzyme responsible for haem detoxification is essential for host protection against these infections (Silva-Gomes et al., 2013a).

One of the ways by which the host can interfere with the pathogen acquisition of iron is through the action of lipocalin (Lcn)-2. Lcn-2, also known as siderocalin, neutrophil gelatinaseassociated lipocalin (NGAL) or $24 \mathrm{p} 3$, is capable of binding siderophores (Goetz et al., 2002) and transport them into cells by endocytosis, after interacting with a specific cell-surface receptor (Devireddy et al., 2005). Lcn-2 is able to bind carboxymycobactin from mycobacteria (Holmes et al., 2005) and inhibit the growth of $M$. tuberculosis and M. bovis BCG in liquid culture, in a dose-dependent manner reversible by the addition of iron or recombinant carboxymycobactin (Saiga et al., 2008). Furthermore, Lcn-2-deficient mice are highly susceptible to intratracheal infection with M. tuberculosis (Saiga et al., 2008). Of note, recent studies have shown that Lcn-2 can also function as an iron shuttle in basal metabolism of the host, either delivering iron to or stealing iron from specific cell types, implicating Lcn-2 in processes unrelated to its function in immunity (Correnti and Strong, 2012).

Inside infected macrophages, pathogen's access to iron may be limited by SLC11A1. SLC11A1 is a divalent metal transporter, recruited to the late endosomal and phagosomal membrane of macrophages and other professional phagocytes (Nevo and Nelson, 2006). Although SLC11A1 contributes to macrophages' efficiency in the recycling of erythrocyte-derived iron (Soe-Lin et al., 2009), the main function of SLC11A1 seems to be the protection against microbes. The Slc1lal gene is present in inbred strains of mice in two allelic forms which determine the resistance or susceptibility to several intracellular pathogens such as Mycobacterium spp., Salmonella spp and Leishmania spp (Vidal et al., 1993). Susceptible mice carry a glycine (G) to aspartic acid (D) substitution at position 169, resulting in a misfolding and loss of function of the protein (White et al., 2004). This mutation confers susceptibility to several mycobacterial species, such as M. avium (Appelberg and Sarmento, 1990; Gomes and Appelberg, 1998), M. intracellulare (Goto et al., 1989), M. bovis BCG (Gros et al., 1981) but not to M. tuberculosis (Medina and North, 1996; North et al., 1999). Although the G169D mutation has never been found in humans, polymorphic variations at or near human SLC11A1 are associated with susceptibility to tuberculosis and leprosy in populations from areas of endemic disease (Fortier et al., 2005). The directionality of metal transport in the SLC11A1 is still not consensual. Some groups suggest that iron is transported via this protein into the pathogen-containing phagosome, causing the death of the pathogen by catalyzing the formation of reactive oxygen species (ROS) (Kuhn et al., 1999, 2001; Zwilling et al., 1999), while others argue for an iron efflux from the phagosome, restricting pathogen growth by iron deprivation (Gomes and Appelberg, 1998; Mulero et al., 2002). Studies of analogy with DMT1 (NRAMP2) (Forbes and Gros, 2003), the resistance of mycobacteria to ROS (Segal et al., 1999; Gomes and Appelberg, 2002) and the role of SLC11A1 in erythrocyte recycling (Soe-Lin et al., 2009) favor the second hypothesis, which is now seen as more consensual in the literature (Schaible and Kaufmann, 2004; Cellier et al., 2007; Wessling-Resnick, 2010).

Another iron transporter expressed in macrophages is ferroportin (SLC40A1). Ferroportin is present in the macrophage cytoplasmic membrane and is responsible for iron export (Knutson et al., 2005). Overexpression of ferroportin was reported to inhibit the intra-macrophagic growth of $M$. tuberculosis presumably through iron deprivation (Johnson et al., 2010). An interplay between the expression of ferroportin and the activation of the macrophage's inducible nitric oxide synthase (NOS2) seems to occur. While the overexpression of ferroportin decreased macrophages nitric oxide production (Johnson et al., 2010), the expression of NOS2 was reported by Nairz et al to be necessary to maintain ferroportin expression and iron efflux (Nairz et al., 2013). In this study, Salmonella residing within nitric oxide synthase deficient $\left(\right.$ Nos $\left.2^{-/-}\right)$macrophages acquired more iron than bacteria within wild-type macrophages and the authors concluded that iron deprivation is the main way through which NOS2 contributes to Salmonella control. However, while M. avium depends on access to iron to proliferate inside macrophages, Nos $2^{-/-}$macrophages and mice are not more permissive to the growth of this mycobacterium (Gomes et al., 1999b), suggesting that the mechanism for the regulation of iron availability by NO during Salmonella infection does not apply to M. avium infections.

\section{IRON METABOLISM IN Leishmania INFECTION}

The leishmaniases are a complex of mammalian diseases characterized by distinct clinical manifestations: cutaneous, mucocutaneous and visceral leishmaniasis. Though considered to be neglected tropical diseases, their global incidence is a worrisome 2 million new cases per year. They are caused by protozoa of the genus Leishmania, whose transmission occurs through the bite of female sandfly. Transmission mediated by the insect may be zoonotic-between reservoir hosts (rodents and canines) and humans-or anthroponotic (Ready, 2010). Disease is not necessarily the final outcome in endemic areas where humans stably share the habitat with wild rodents, dogs and the sand fly populations as asymptomatic infections may occur.

Leishmania parasites have a digenetic life cycle, alternating between the promastigote stage in the insect gut and the amastigote stage in macrophages of mammalian hosts. Although Leishmania can infect diverse host cells (e.g., dendritic cells and 
neutrophils), there is only evidence for replication and long-term survival within mononuclear phagocytes (Kaye and Scott, 2011).

\section{HOST IRON STATE: EVIDENCES FROM HUMAN AND CANINE STUDIES}

A direct link between host iron status and human or canine susceptibility to Leishmania infection is not clearly found from available epidemiologic data. The fact that several studies found an association between susceptibility to leishmaniasis and polymorphisms in the SLC11A1 gene, which codes for a transmembrane transporter of iron and other divalent metals, as mentioned before (Altet et al., 2002; Bucheton et al., 2003; Sanchez-Robert et al., 2008; Blackwell et al., 2009; Castellucci et al., 2010) and, on the other hand, the generalized association between leishmaniasis and malnutrition (Maciel et al., 2008; McCall et al., 2013) are indirect evidences that the host iron status may influence the outcome of the Leishmania infection. However, more direct correlations can only be made based on the studies performed in several infection models.

\section{HOST IRON STATE: EVIDENCES FROM RODENT MODELS}

Despite the lack of direct clinical evidences, we could expect iron to favor the growth of Leishmania, similarly to what is found for other pathogens (Weinberg, 2009). The fact that these parasites are equipped with diverse iron acquisition mechanisms and are capable of utilizing various iron sources suggested that iron acquisition was essential for pathogenicity and that iron deprivation could be an effective strategy to control leishmanial infections (Sutak et al., 2008; Taylor and Kelly, 2010). Such hypothesis is supported by the finding that the iron chelators desferrioxamine (DFO) and hydroxypyridin-4-ones moderately inhibit the multiplication of L. major and L. infantum promastigotes in culture medium (Soteriadou et al., 1995). However, DFO has shown either no effect (Murray et al., 1991) or an inhibitory effect on the intramacrophagic growth of L. donovani (Segovia et al., 1989; Das et al., 2009) and L. amazonensis (Borges et al., 1998). Moreover, treatment of mice with DFO does not affect the development of skin lesions caused by L. major (Bisti et al., 2000), but reduces the hepatic and splenic growth of $L$. infantum (Malafaia et al., 2011). Conversely, feeding mice with an iron-deficient diet did not influence L. infantum proliferation (Vale-Costa et al., 2013). Overall, the existing studies do not thoroughly support the notion that iron depletion contributes to the control of leishmanial infections.

Data obtained in cellulo concerning the impact of iron supplementation is also not consensual. Iron treatment either favored the intramacrophagic growth of L. donovani (Das et al., 2009) and L. amazonensis (Borges et al., 1998) and reversed the capacity of activated macrophages to eliminate L. enriettii (Mauel et al., 1991) or had no influence on both effects (Murray et al., 1991). Interestingly, the role of this nutrient on the in vivo growth of the parasite seems to be dependent on the host species. Iron given to hamsters prophylactically or therapeutically enhanced L. donovani replication (Garg et al., 2004). By contrast, in vivo iron administration to susceptible mice clearly leads to containment of L. major in the skin (Bisti et al., 2000, 2006; Bisti and Soteriadou, 2006) and L. infantum in the liver and spleen (ValeCosta et al., 2013). The anti-leishmanial effect of iron is most likely due to its synergistic interaction with reactive oxygen and nitrogen species produced by the host's professional phagocytes (Bisti et al., 2006; Vale-Costa et al., 2013). Furthermore, the control of L. major infection, but not that of L. infantum, by iron also correlates with the development of a T helper 1 (Th1)-type immune response (Bisti et al., 2000), which is characterized by (i) an increased ability of splenic cells to present $L$. major-derived peptides, (ii) increased levels of IFN $\gamma$ and NOS2 and decreased levels of IL-4 and IL-10 transcripts at the lesion site and (iii) reduced levels of serum immunoglobulin (Ig) E and IgG1 and increased levels of IgG2a (Bisti et al., 2000). Notably, iron overloaded mice are also resistant to re-infection with L. major (Bisti and Soteriadou, 2006). The iron-induced oxidative burst elicited during both primary and secondary infections with $L$. major is linked to the activation of the transcription factor NF- $\kappa \mathrm{B}$ and with an enhanced proliferation of IFN $\gamma$-secreting CD $4^{+} \mathrm{T}$ cells in the draining lymph nodes (Bisti and Soteriadou, 2006). This is substantiated by the fact that iron and reactive oxygen and nitrogen species can modulate the activation of macrophagic NF- $\kappa$ B signaling pathways (Xiong et al., 2003; Leonard et al., 2004; Galaris and Pantopoulos, 2008) which are known to regulate numerous genes involved in immune and inflammatory responses (Bonizzi and Karin, 2004). Indeed, NF- $\kappa \mathrm{B}$ regulates the development of IFN $\gamma$-secreting $\mathrm{CD}^{+} \mathrm{T}$ cells and concomitant resistance to $L$. major (Artis et al., 2003). Hence, iron not only seems to synergize with the host's oxidative mechanisms of defense, but also interacts with reactive oxygen and nitrogen species in order to activate signaling cascades that regulate the development of protective immunity against Leishmania.

The abovementioned reports clearly indicate that iron induces host protection against Leishmania infection. Future research should seek a confirmation of the inhibitory effect of iron on the in vivo growth of other Leishmania species and a better understanding of the molecular pathways involved in the iron-induced resistance against these protozoa.

\section{THE FIGHT FOR IRON}

Like many other intracellular pathogens, Leishmania must be capable of acquiring iron from the host milieu in order to thrive. Besides holotransferrin (Borges et al., 1998), the growth and survival of L. infantum and L. amazonensis amastigotes can be supported by iron derived from haemoglobin and hemin (Carvalho et al., 2009). The uptake of haem by intramacrophagic L. amazonensis amastigotes is mediated by Leishmania haem response 1 (LHR1) protein (Huynh et al., 2012). Furthermore, intracellular L. amazonensis also possesses a ferric reductase, the Leishmania ferric iron reductase 1 (LFR1) (Flannery et al., 2011) which provides soluble ferrous iron for transport across the parasite plasma membrane by the ferrous iron transporter Leishmania iron transporter 1 (LIT1) (Huynh et al., 2006; Jacques et al., 2010). Moreover, LIT1-mediated iron acquisition seems to be essential for the differentiation of L. amazonensis parasites from the sandfly promastigote form to the macrophage-adapted amastigote form (Mittra et al., 2013).

Apart from the mechanisms of direct iron internalization, Leishmania parasites can also subvert the host's iron uptake systems to their own advantage. In fact, L. amazonensis amastigotes 
can obtain transferrin by forcing the fusion of transferrincontaining endosomes with the parasitophorous vacuole (Borges et al., 1998). Alternatively, L. donovani is capable of decreasing the macrophage labile iron pool, a process that triggers an increased surface expression of transferrin receptor 1 and internalization of transferrin, thus permitting a continuous provision of iron to the parasite (Das et al., 2009). This decrease in labile iron pool of activated macrophages has been recently proposed to be the result of the down-regulation of the expression of SLC11A1 by a L. donovani-secreted peroxidase (Singh et al., 2013). Also in line with these data, it has been reported that the expression of ferroportin is down-regulated in the spleen of $L$. donovani-infected mice, which may contribute to an increased accumulation of iron inside macrophages (Yang et al., 2002).

The existence of a parasitic strategy to counteract host SLC11A1 action reinforces the involvement of the latter in the in vivo control of infection by Leishmania (Vidal et al., 1995; Searle et al., 1998; White et al., 2005), as mentioned previously. This protein has also been implicated in the response to vaccination. Mice with functional SLC11A1 mount primarily a Th1 response to vaccination with the parasite metalloprotease Gp63 and display decreased skin lesions during a challenge infection with $L$. major. In striking contrast, mice with mutated SLC11A1 exhibit a Th2 response and an exacerbated lesion growth upon challenge (Soo et al., 1998).

Finally, we should acknowledge that the involvement of other host mechanisms of iron deprivation during leishmanial infections is largely unknown.

\section{IRON DEPRIVATION vs. IRON-INDUCED TOXICITY}

As the number of antibiotic resistant pathogens increases and the discovery of new antibiotics declines, the understanding of critical pathways in host-pathogen interaction emerges as a promising source of new approaches to fight infections. The modulation of iron availability may be one of such pathways. However, it should be noted that the choice of whether to provide or to deprive the pathogen of iron clearly depends on the microorganism in question.

The first widely used treatments for leishmaniasis relied on the administration of antimony complexes. Not excluding other possible mechanisms of action, strong evidences suggest that antimony compounds kill Leishmania parasites through the increased generation of ROS in the host (Ait-Oudhia et al., 2011) similarly to what we and others recently described for iron (Bisti et al., 2006; Vale-Costa et al., 2013). Of interest, other metal-containing drugs continue to be described as potential new therapies against Leishmania (Vale-Costa et al., 2012; Rocha et al., 2013). The main concern raised by these metal-providing tools is obviously the inherent toxicity of the metals associated with their propensity to induce oxidative stress. One of the possible ways to circumvent this problem will be to use new specific delivery systems to target the drug to infected macrophages.

In the case of mycobacterial infections, it is well-established that iron deprivation inhibits pathogen proliferation and iron depriving strategies seem the most promising in therapeutic terms. However, the administration of iron chelators is not exempt from risks to the host, especially in a context where the latter activates a series of iron withholding mechanisms which may lead to anaemia. The findings of the last decade on the players that control host iron metabolism, notably the identification of the iron exporter ferroportin and the hormone hepcidin, have opened new and exciting possibilities for the modulation of iron availability and localization inside cells which should provide ways of specifically depriving intracellular pathogens, without hampering the normal iron homeostasis of the host.

\section{FUNDING}

Project "NORTE-07-0124-FEDER-000002-Host-Pathogen Interactions" co-funded by Programa Operacional Regional do Norte (ON.2-O Novo Norte), under the Quadro de Referência Estratégico Nacional (QREN), through the Fundo Europeu de Desenvolvimento Regional (FEDER) and by FCT (Fundação para a Ciência e Tecnologia).

\section{REFERENCES}

Ait-Oudhia, K., Gazanion, E., Vergnes, B., Oury, B., and Sereno, D. (2011). Leishmania antimony resistance: what we know what we can learn from the field. Parasitol. Res. 109, 1225-1232. doi: 10.1007/s00436-011-2555-5

Altet, L., Francino, O., Solano-Gallego, L., Renier, C., and Sanchez, A. (2002). Mapping and sequencing of the canine NRAMP1 gene and identification of mutations in leishmaniasis-susceptible dogs. Infect. Immun. 70, 2763-2771. doi: 10.1128/IAI.70.6.2763-2771.2002

Andreini, C., Bertini, I., Cavallaro, G., Holliday, G. L., and Thornton, J. M. (2008). Metal ions in biological catalysis: from enzyme databases to general principles. J. Biol. Inorg. Chem. 13, 1205-1218. doi: 10.1007/s00775-008-0404-5

Andrews, N. C., and Schmidt, P. J. (2007). Iron homeostasis. Annu. Rev. Physiol. 69, 69-85. doi: 10.1146/annurev.physiol.69.031905.164337

Appelberg, R. (2006a). Macrophage nutriprive antimicrobial mechanisms. J. Leukoc. Biol. 79, 1117-1128. doi: 10.1189/jlb.0206079

Appelberg, R. (2006b). Pathogenesis of Mycobacterium avium infection: typical responses to an atypical mycobacterium? Immunol. Res. 35, 179-190. doi: 10.1385/IR:35:3:179

Appelberg, R., and Sarmento, A. M. (1990). The role of macrophage activation and of Bcg-encoded macrophage function(s) in the control of Mycobacterium avium infection in mice. Clin. Exp. Immunol. 80, 324-331. doi: 10.1111/j.13652249.1990.tb03288.x

Artis, D., Speirs, K., Joyce, K., Goldschmidt, M., Caamano, J., Hunter, C. A., et al. (2003). NF-kappa B1 is required for optimal CD4+ Th1 cell development and resistance to Leishmania major. J. Immunol. 170, 1995-2003.

Bisti, S., Konidou, G., Boelaert, J., Lebastard, M., and Soteriadou, K. (2006). The prevention of the growth of Leishmania major progeny in BALB/c iron-loaded mice: a process coupled to increased oxidative burst, the amplitude and duration of which depend on initial parasite developmental stage and dose. Microbes Infect. 8, 1464-1472. doi: 10.1016/j.micinf.2006.01.014

Bisti, S., Konidou, G., Papageorgiou, F., Milon, G., Boelaert, J. R., and Soteriadou, K. (2000). The outcome of Leishmania major experimental infection in BALB/c mice can be modulated by exogenously delivered iron. Eur. J. Immunol. 30, 3732-3740. doi: 10.1002/1521-4141(200012)30:12<3732::AIDIMMU3732>3.0.CO;2-D

Bisti, S., and Soteriadou, K. (2006). Is the reactive oxygen species-dependentNF-kappaB activation observed in iron-loaded BALB/c mice a key process preventing growth of Leishmania major progeny and tissue-damage? Microbes Infect. 8, 1473-1482. doi: 10.1016/j.micinf.2006.01.004

Blackwell, J. M., Fakiola, M., Ibrahim, M. E., Jamieson, S. E., Jeronimo, S. B., Miller, E. N., et al. (2009). Genetics and visceral leishmaniasis: of mice and man. Parasite Immunol. 31, 254-266. doi: 10.1111/j.1365-3024.2009.01102.x

Bonizzi, G., and Karin, M. (2004). The two NF-kappaB activation pathways and their role in innate and adaptive immunity. Trends Immunol. 25, 280-288. doi: 10.1016/j.it.2004.03.008

Borges, V. M., Vannier-Santos, M. A., and De Souza, W. (1998). Subverted transferrin trafficking in Leishmania-infected macrophages. Parasitol. Res. 84, 811-822. doi: $10.1007 /$ s004360050493 
Botella, H., Peyron, P., Levillain, F., Poincloux, R., Poquet, Y., Brandli, I., et al. (2011). Mycobacterial $\mathrm{p}(1)$-type ATPases mediate resistance to zinc poisoning in human macrophages. Cell Host Microbe 10, 248-259. doi: 10.1016/j.chom.2011.08.006

Bucheton, B., Abel, L., Kheir, M. M., Mirgani, A., El-Safi, S. H., Chevillard, C., et al. (2003). Genetic control of visceral leishmaniasis in a Sudanese population: candidate gene testing indicates a linkage to the NRAMP1 region. Genes Immun. 4, 104-109. doi: 10.1038/sj.gene.6363927

Carvalho, S., Cruz, T., Santarem, N., Castro, H., Costa, V., and Tomas, A. M. (2009). Heme as a source of iron to Leishmania infantum amastigotes. Acta Trop. 109, 131-135. doi: 10.1016/j.actatropica.2008.10.007

Castellucci, L., Jamieson, S. E., Miller, E. N., Menezes, E., Oliveira, J., Magalhaes, A., et al. (2010). CXCR1 and SLC11A1 polymorphisms affect susceptibility to cutaneous leishmaniasis in Brazil: a case-control and family-based study. BMC Med. Genet. 11:10. doi: 10.1186/1471-2350-11-10

Cellier, M. F., Courville, P., and Campion, C. (2007). Nramp1 phagocyte intracellular metal withdrawal defense. Microbes Infect. 9, 1662-1670. doi: 10.1016/j.micinf.2007.09.006

Clemens, D. L., and Horwitz, M. A. (1996). The Mycobacterium tuberculosis phagosome interacts with early endosomes and is accessible to exogenously administered transferrin. J. Exp. Med. 184, 1349-1355. doi: 10.1084/jem.184.4.1349

Cooper, A. M. (2009). Cell-mediated immune responses in tuberculosis. Annu. Rev. Immunol. 27, 393-422. doi: 10.1146/annurev.immunol.021908.132703

Correnti, C., and Strong, R. K. (2012). Mammalian siderophores, siderophorebinding lipocalins, and the labile iron pool. J. Biol. Chem. 287, 13524-13531. doi: $10.1074 /$ jbc.R111.311829

Crichton, R. R., and Pierre, J. L. (2001). Old iron, young copper: from Mars to Venus. Biometals 14, 99-112. doi: 10.1023/A:1016710810701

Das, N. K., Biswas, S., Solanki, S., and Mukhopadhyay, C. K. (2009). Leishmania donovani depletes labile iron pool to exploit iron uptake capacity of macrophage for its intracellular growth. Cell. Microbiol. 11, 83-94. doi: 10.1111/j.14625822.2008.01241.x

Deschemin, J. C., and Vaulont, S. (2013). Role of hepcidin in the setting of hypoferremia during acute inflammation. PLOS ONE 8:e61050. doi: 10.1371/journal.pone.0061050

De Sousa, M., Reimao, R., Lacerda, R., Hugo, P., Kaufmann, S. H., and Porto, G. (1994). Iron overload in beta 2-microglobulin-deficient mice. Immunol. Lett. 39, 105-111. doi: 10.1016/0165-2478(94)90094-9

Devireddy, L. R., Gazin, C., Zhu, X., and Green, M. R. (2005). A cell-surface receptor for lipocalin $24 \mathrm{p} 3$ selectively mediates apoptosis and iron uptake. Cell 123, 1293-1305. doi: 10.1016/j.cell.2005.10.027

De Voss, J. J., Rutter, K., Schroeder, B. G., Su, H., Zhu, Y., and Barry, C. E. 3rd (2000). The salicylate-derived mycobactin siderophores of Mycobacterium tuberculosis are essential for growth in macrophages. Proc. Natl. Acad. Sci. U.S.A. 97, 1252-1257. doi: 10.1073/pnas.97.3.1252

Fernandes, S. S., Nunes, A., Gomes, A. R., De Castro, B., Hider, R. C., Rangel, M., et al. (2010). Identification of a new hexadentate iron chelator capable of restricting the intramacrophagic growth of Mycobacterium avium. Microbes Infect. 12, 287-294. doi: 10.1016/j.micinf.2010.01.003

Ferreras, J. A., Gupta, A., Amin, N. D., Basu, A., Sinha, B. N., Worgall, S., et al. (2011). Chemical scaffolds with structural similarities to siderophores of nonribosomal peptide-polyketide origin as novel antimicrobials against Mycobacterium tuberculosis and Yersinia pestis. Bioorg. Med. Chem. Lett. 21, 6533-6537. doi: 10.1016/j.bmcl.2011.08.052

Ferreras, J. A., Ryu, J. S., Di Lello, F., Tan, D. S., and Quadri, L. E. (2005). Smallmolecule inhibition of siderophore biosynthesis in Mycobacterium tuberculosis and Yersinia pestis. Nat. Chem. Biol. 1, 29-32. doi: 10.1038/nchembio706

Flannery, A. R., Huynh, C., Mittra, B., Mortara, R. A., and Andrews, N. W. (2011). LFR1 ferric iron reductase of Leishmania amazonensis is essential for the generation of infective parasite forms. J. Biol. Chem. 286, 23266-23279. doi: 10.1074/jbc.M111.229674

Flynn, J. L., Goldstein, M. M., Triebold, K. J., Koller, B., and Bloom, B. R. (1992). Major histocompatibility complex class I-restricted T cells are required for resistance to Mycobacterium tuberculosis infection. Proc. Natl. Acad. Sci. U.S.A. 89, 12013-12017. doi: 10.1073/pnas.89.24.12013

Forbes, J. R., and Gros, P. (2003). Iron, manganese, and cobalt transport by Nramp1 (Slc11a1) and Nramp2 (Slc1la2) expressed at the plasma membrane. Blood 102, 1884-1892. doi: 10.1182/blood-2003-02-0425
Fortier, A., Min-Oo, G., Forbes, J., Lam-Yuk-Tseung, S., and Gros, P. (2005). Single gene effects in mouse models of host: pathogen interactions. J. Leukoc. Biol. 77, 868-877. doi: 10.1189/jlb.1004616

Galaris, D., and Pantopoulos, K. (2008). Oxidative stress and iron homeostasis: mechanistic and health aspects. Crit. Rev. Clin. Lab. Sci. 45, 1-23. doi: $10.1080 / 10408360701713104$

Gangaidzo, I. T., Moyo, V. M., Mvundura, E., Aggrey, G., Murphree, N. L., Khumalo, H., et al. (2001). Association of pulmonary tuberculosis with increased dietary iron. J. Infect. Dis. 184, 936-939. doi: 10.1086/323203

Ganz, T., and Nemeth, E. (2012a). Hepcidin and iron homeostasis. Biochim. Biophys. Acta 1823, 1434-1443. doi: 10.1016/j.bbamcr.2012.01.014

Ganz, T., and Nemeth, E. (2012b). Iron metabolism: interactions with normal and disordered erythropoiesis. Cold Spring Harb. Perspect. Med. 2, a011668. doi: $10.1101 /$ cshperspect.a011668

Garg, R., Singh, N., and Dube, A. (2004). Intake of nutrient supplements affects multiplication of Leishmania donovani in hamsters. Parasitology 129, 685-691. doi: $10.1017 /$ S0031182004006055

Gobin, J., and Horwitz, M. A. (1996). Exochelins of Mycobacterium tuberculosis remove iron from human iron-binding proteins and donate iron to mycobactins in the M. tuberculosis cell wall. J. Exp. Med. 183, 1527-1532. doi: 10.1084/jem.183.4.1527

Goetz, D. H., Holmes, M. A., Borregaard, N., Bluhm, M. E., Raymond, K. N., and Strong, R. K. (2002). The neutrophil lipocalin NGAL is a bacteriostatic agent that interferes with siderophore-mediated iron acquisition. Mol. Cell 10, 1033-1043. doi: 10.1016/S1097-2765(02)00708-6

Gomes, M. S., and Appelberg, R. (1998). Evidence for a link between iron metabolism and Nrampl gene function in innate resistance against Mycobacterium avium. Immunology 95, 165-168. doi: 10.1046/j.1365-2567.1998.00630.x

Gomes, M. S., and Appelberg, R. (2002). NRAMP1- or cytokine-induced bacteriostasis of Mycobacterium avium by mouse macrophages is independent of the respiratory burst. Microbiology 148, 3155-3160.

Gomes, M. S., Boelaert, J. R., and Appelberg, R. (2001). Role of iron in experimental Mycobacterium avium infection. J. Clin. Virol. 20, 117-122. doi: 10.1016/S13866532(00)00135-9

Gomes, M. S., Dom, G., Pedrosa, J., Boelaert, J. R., and Appelberg, R. (1999a). Effects of iron deprivation on Mycobacterium avium growth. Tuber. Lung Dis. 79, 321-328. doi: 10.1054/tuld.1999.0216

Gomes, M. S., Florido, M., Pais, T. F., and Appelberg, R. (1999b). Improved clearance of Mycobacterium avium upon disruption of the inducible nitric oxide synthase gene. J. Immunol. 162, 6734-6739.

Gomes-Pereira, S., Rodrigues, P. N., Appelberg, R., and Gomes, M. S. (2008). Increased susceptibility to Mycobacterium avium in hemochromatosis protein HFE-deficient mice. Infect. Immun. 76, 4713-4719. doi: 10.1128/IAI.00612-08

Gordeuk, V. R., McLaren, C. E., Macphail, A. P., Deichsel, G., and Bothwell, T. H. (1996). Associations of iron overload in Africa with hepatocellular carcinoma and tuberculosis: Strachan's 1929 thesis revisited. Blood 87, 3470-3476.

Goto, Y., Buschman, E., and Skamene, E. (1989). Regulation of host resistance to Mycobacterium intracellulare in vivo and in vitro by the Bcg gene. Immunogenetics 30, 218-221. doi: 10.1007/BF02421210

Gros, P., Skamene, E., and Forget, A. (1981). Genetic control of natural resistance to Mycobacterium bovis (BCG) in mice. J. Immunol. 127, 2417-2421.

Halaas, O., Steigedal, M., Haug, M., Awuh, J. A., Ryan, L., Brech, A., et al. (2010). Intracellular Mycobacterium avium intersect transferrin in the Rab11(+) recycling endocytic pathway and avoid lipocalin 2 trafficking to the lysosomal pathway. J. Infect. Dis. 201, 783-792. doi: 10.1086/650493

Harrison, P. M., and Arosio, P. (1996). The ferritins: molecular properties, iron storage function and cellular regulation. Biochim. Biophys. Acta 1275, 161-203. doi: 10.1016/0005-2728(96)00022-9

Hider, R. C., and Kong, X. (2010). Chemistry and biology of siderophores. Nat. Prod. Rep. 27, 637-657. doi: 10.1039/b906679a

Hodgkinson, V., and Petris, M. J. (2012). Copper homeostasis at the host-pathogen interface. J. Biol. Chem. 287, 13549-13555. doi: 10.1074/jbc.R111.316406

Holmes, M. A., Paulsene, W., Jide, X., Ratledge, C., and Strong, R. K. (2005). Siderocalin ( $\operatorname{Lcn} 2$ ) also binds carboxymycobactins, potentially defending against mycobacterial infections through iron sequestration. Structure 13, 29-41. doi: 10.1016/j.str.2004.10.009 
Hood, M. I., and Skaar, E. P. (2012). Nutritional immunity: transition metals at the pathogen-host interface. Nat. Rev. Microbiol. 10, 525-537. doi: 10.1038/nrmicro2836

Huynh, C., Sacks, D. L., and Andrews, N. W. (2006). A Leishmania amazonensis ZIP family iron transporter is essential for parasite replication within macrophage phagolysosomes. J. Exp. Med. 203, 2363-2375. doi: 10.1084/jem.20060559

Huynh, C., Yuan, X., Miguel, D. C., Renberg, R. L., Protchenko, O., Philpott, C. C., et al. (2012). Heme uptake by Leishmania amazonensis is mediated by the transmembrane protein LHR1. PLoS Pathog. 8:e1002795. doi: 10.1371/journal.ppat. 1002795

Jacques, I., Andrews, N. W., and Huynh, C. (2010). Functional characterization of LIT1, the Leishmania amazonensis ferrous iron transporter. Mol. Biochem. Parasitol. 170, 28-36. doi: 10.1016/j.molbiopara.2009.12.003

Johnson, E. E., Sandgren, A., Cherayil, B. J., Murray, M., and Wessling-Resnick, M. (2010). Role of ferroportin in macrophage-mediated immunity. Infect. Immun. 78, 5099-5106. doi: 10.1128/IAI.00498-10

Jones, C. M., and Niederweis, M. (2011). Mycobacterium tuberculosis can utilize heme as an iron source. J. Bacteriol. 193, 1767-1770. doi: 10.1128/JB.01312-10

Kaplan, J., and Ward, D. M. (2013). The essential nature of iron usage and regulation. Curr. Biol. 23, R642-R646. doi: 10.1016/j.cub.2013.05.033

Kaye, P., and Scott, P. (2011). Leishmaniasis: complexity at the host-pathogen interface. Nat. Rev. Microbiol. 9, 604-615. doi: 10.1038/nrmicro2608

Kehl-Fie, T. E., and Skaar, E. P. (2010). Nutritional immunity beyond iron: a role for manganese and zinc. Curr. Opin. Chem. Biol. 14, 218-224. doi: 10.1016/j.cbpa.2009.11.008

Kelley, V. A., and Schorey, J. S. (2003). Mycobacterium's arrest of phagosome maturation in macrophages requires Rab5 activity and accessibility to iron. Mol. Biol. Cell 14, 3366-3377. doi: 10.1091/mbc.E02-12-0780

Knutson, M. D., Oukka, M., Koss, L. M., Aydemir, F., and Wessling-Resnick, M. (2005). Iron release from macrophages after erythrophagocytosis is upregulated by ferroportin 1 overexpression and down-regulated by hepcidin. Proc. Natl. Acad. Sci. U.S.A. 102, 1324-1328. doi: 10.1073/pnas.0409409102

Kuhn, D. E., Baker, B. D., Lafuse, W. P., and Zwilling, B. S. (1999). Differential iron transport into phagosomes isolated from the RAW264.7 macrophage cell lines transfected with Nramp1Gly169 or Nramp1Asp169. J. Leukoc. Biol. 66, 113-119.

Kuhn, D. E., Lafuse, W. P., and Zwilling, B. S. (2001). Iron transport into mycobacterium avium-containing phagosomes from an Nramp1(Gly169)-transfected RAW264.7 macrophage cell line. J. Leukoc. Biol. 69, 43-49.

Laftah, A. H., Sharma, N., Brookes, M. J., McKie, A. T., Simpson, R. J., Iqbal, T. H., et al. (2006). Tumour necrosis factor alpha causes hypoferraemia and reduced intestinal iron absorption in mice. Biochem. J. 397, 61-67. doi: 10.1042/BJ20060215

Larsen, R., Gozzelino, R., Jeney, V., Tokaji, L., Bozza, F. A., Japiassu, A. M., et al. (2010). A central role for free heme in the pathogenesis of severe sepsis. Sci. Transl. Med. 2, 51ra71. doi: 10.1126/scitranslmed.3001118

Layoun, A., Huang, H., Calve, A., and Santos, M. M. (2012). Toll-like receptor signal adaptor protein MyD88 is required for sustained endotoxin-induced acute hypoferremic response in mice. Am. J. Pathol. 180, 2340-2350. doi: 10.1016/j.ajpath.2012.01.046

Lee, S. W., Kang, Y. A., Yoon, Y. S., Um, S. W., Lee, S. M., Yoo, C. G., et al. (2006). The prevalence and evolution of anemia associated with tuberculosis. J. Korean Med. Sci. 21, 1028-1032. doi: 10.3346/jkms.2006.21.6.1028

Leonard, S. S., Harris, G. K., and Shi, X. (2004). Metal-induced oxidative stress and signal transduction. Free Radic. Biol. Med. 37, 1921-1942. doi: 10.1016/j.freeradbiomed.2004.09.010

Lounis, N., Maslo, C., Boelaert, J. R., Bonnafous, P., Truffot-Pernot, C., Baohong, J., et al. (1999). Impact of iron loading and iron chelation on murine tuberculosis. Clin. Microbiol. Infect. 5, 687-692. doi: 10.1111/j.1469-0691.1999.tb00514.x

Lounis, N., Maslo, C., Truffot-Pernot, C., Grosset, J., and Boelaert, R. J. (2003). Impact of iron loading on the activity of isoniazid or ethambutol in the treatment of murine tuberculosis. Int. J. Tuberc. Lung Dis. 7, 575-579.

Lounis, N., Truffot-Pernot, C., Grosset, J., Gordeuk, V. R., and Boelaert, J. R. (2001). Iron and Mycobacterium tuberculosis infection. J. Clin. Virol. 20, 123-126. doi: 10.1016/S1386-6532(00)00136-0

Lun, S., Guo, H., Adamson, J., Cisar, J. S., Davis, T. D., Chavadi, S. S., et al. (2013). Pharmacokinetic and in vivo efficacy studies of the Mycobactin biosynthesis inhibitor Salicyl-AMS in Mice. Antimicrob. Agents Chemother. 57, 5138-5140. doi: 10.1128/AAC.00918-13
Maciel, B. L., Lacerda, H. G., Queiroz, J. W., Galvao, J., Pontes, N. N., Dimenstein, R., et al. (2008). Association of nutritional status with the response to infection with Leishmania chagasi. Am. J. Trop. Med. Hyg. 79, 591-598.

Malafaia, G., Marcon Lde, N., Pereira Lde, F., Pedrosa, M. L., and Rezende, S. A. (2011). Leishmania chagasi: effect of the iron deficiency on the infection in BALB/c mice. Exp. Parasitol. 127, 719-723. doi: 10.1016/j.exppara.2010. 11.010

Marchal, G., and Milon, G. (1981). Decreased erythropoiesis: the origin of the BCG induced anaemia in mice. Br. J. Haematol. 48, 551-560. doi: 10.1111/j.13652141.1981.tb02752.x

Mauel, J., Ransijn, A., and Buchmuller-Rouiller, Y. (1991). Killing of Leishmania parasites in activated murine macrophages is based on an L-argininedependent process that produces nitrogen derivatives. J. Leukoc. Biol. 49, 73-82.

McCall, L. I., Zhang, W. W., and Matlashewski, G. (2013). Determinants for the development of visceral leishmaniasis disease. PLoS Pathog. 9:e1003053. doi: 10.1371/journal.ppat.1003053

McDermid, J. M., Hennig, B. J., Van Der Sande, M., Hill, A. V., Whittle, H. C., Jaye, A., et al. (2013). Host iron redistribution as a risk factor for incident tuberculosis in HIV infection: an 11-year retrospective cohort study. BMC Infect. Dis. 13:48. doi: 10.1186/1471-2334-13-48

Medina, E., and North, R. J. (1996). Evidence inconsistent with a role for the Bcg gene (Nramp1) in resistance of mice to infection with virulent Mycobacterium tuberculosis. J. Exp. Med. 183, 1045-1051. doi: 10.1084/jem.183.3.1045

Meyer, D. (2006). Iron chelation as therapy for HIV and Mycobacterium tuberculosis co-infection under conditions of iron overload. Curr. Pharm. Des. 12, 1943-1947. doi: 10.2174/138161206777442164

Mittra, B., Cortez, M., Haydock, A., Ramasamy, G., Myler, P. J., and Andrews, N. W. (2013). Iron uptake controls the generation of Leishmania infective forms through regulation of ROS levels. J. Exp. Med. 210, 401-416. doi: 10.1084/jem.20121368

Moniz, T., Nunes, A., Silva, A. M., Queiros, C., Ivanova, G., Gomes, M. S., et al. (2013). Rhodamine labeling of 3-hydroxy-4-pyridinone iron chelators is an important contribution to target Mycobacterium avium infection. J. Inorg. Biochem. 121, 156-166. doi: 10.1016/j.jinorgbio.2013.01.002

Mulero, V., Searle, S., Blackwell, J. M., and Brock, J. H. (2002). Solute carrier 1la1 (Slc1la1; formerly Nramp1) regulates metabolism and release of iron acquired by phagocytic, but not transferrin-receptor-mediated, iron uptake. Biochem. J. 363, 89-94. doi: 10.1042/0264-6021:3630089

Murray, H. W., Granger, A. M., and Teitelbaum, R. F. (1991). Gamma interferonactivated human macrophages and Toxoplasma gondii, Chlamydia psittaci, and Leishmania donovani: antimicrobial role of limiting intracellular iron. Infect. Immun. 59, 4684-4686.

Nairz, M., Schleicher, U., Schroll, A., Sonnweber, T., Theurl, I., Ludwiczek, S., et al. (2013). Nitric oxide-mediated regulation of ferroportin-1 controls macrophage iron homeostasis and immune function in Salmonella infection. J. Exp. Med. 210, 855-873. doi: 10.1084/jem.20121946

Nairz, M., Theurl, I., Ludwiczek, S., Theurl, M., Mair, S. M., Fritsche, G., et al. (2007). The co-ordinated regulation of iron homeostasis in murine macrophages limits the availability of iron for intracellular Salmonella typhimurium. Cell. Microbiol. 9, 2126-2140. doi: 10.1111/j.1462-5822.2007.00942.x

Nambu, S., Matsui, T., Goulding, C. W., Takahashi, S., and Ikeda-Saito, M. (2013). A new way to degrade heme: the Mycobacterium tuberculosis enzyme MhuD catalyzes heme degradation without generating CO. J. Biol. Chem. 288, 10101-10109. doi: 10.1074/jbc.M112.448399

Nevo, Y., and Nelson, N. (2006). The NRAMP family of metal-ion transporters. Biochim. Biophys. Acta 1763, 609-620. doi: 10.1016/j.bbamcr.2006.05.007

Nguyen, K. T., Wu, J. C., Boylan, J. A., Gherardini, F. C., and Pei, D. (2007). Zinc is the metal cofactor of Borrelia burgdorferi peptide deformylase. Arch. Biochem. Biophys. 468, 217-225. doi: 10.1016/j.abb.2007.09.023

North, R. J., Lacourse, R., Ryan, L., and Gros, P. (1999). Consequence of Nramp1 deletion to Mycobacterium tuberculosis infection in mice. Infect. Immun. 67, 5811-5814.

Nunes, A., Podinovskaia, M., Leite, A., Gameiro, P., Zhou, T., Ma, Y., et al. (2010). Fluorescent 3-hydroxy-4-pyridinone hexadentate iron chelators: intracellular distribution and the relevance to antimycobacterial properties. J. Biol. Inorg. Chem. 15, 861-877. doi: 10.1007/s00775-010-0650-1 
Olakanmi, O., Schlesinger, L. S., Ahmed, A., and Britigan, B. E. (2002). Intraphagosomal Mycobacterium tuberculosis acquires iron from both extracellular transferrin and intracellular iron pools. J. Biol. Chem. 277, 49727-49734. doi: 10.1074/jbc.M209768200

Olakanmi, O., Schlesinger, L. S., Ahmed, A., and Britigan, B. E. (2004). The nature of extracellular iron influences iron acquisition by Mycobacterium tuberculosis residing within human macrophages. Infect. Immun. 72, 2022-2028. doi: 10.1128/IAI.72.4.2022-2028.2004

Olakanmi, O., Schlesinger, L. S., and Britigan, B. E. (2007). Hereditary hemochromatosis results in decreased iron acquisition and growth by Mycobacterium tuberculosis within human macrophages. J. Leukoc. Biol. 81, 195-204. doi: 10.1189/jlb.0606405

Posey, J. E., and Gherardini, F. C. (2000). Lack of a role for iron in the Lyme disease pathogen. Science 288, 1651-1653. doi: 10.1126/science.288.5471.1651

Quadri, L. E., Sello, J., Keating, T. A., Weinreb, P. H., and Walsh, C. T. (1998). Identification of a Mycobacterium tuberculosis gene cluster encoding the biosynthetic enzymes for assembly of the virulence-conferring siderophore mycobactin. Chem. Biol. 5, 631-645. doi: 10.1016/S1074-5521(98)90291-5

Ratledge, C. (2004). Iron, mycobacteria and tuberculosis. Tuberculosis 84, 110-130. doi: 10.1016/j.tube.2003.08.012

Ready, P. D. (2010). Leishmaniasis emergence in Europe. Euro Surveill. 15, 19505

Recalcati, S., Locati, M., and Cairo, G. (2012). Systemic and cellular consequences of macrophage control of iron metabolism. Semin. Immunol. 24, 393. doi: 10.1016/j.smim.2013.01.001

Reddy, P. V., Puri, R. V., Chauhan, P., Kar, R., Rohilla, A., Khera, A., and Tyagi, A. K. (2013). Disruption of Mycobactin biosynthesis leads to attenuation of Mycobacterium tuberculosis for growth and virulence. J. Infect. Dis. 208, 1255-1265. doi: 10.1093/infdis/jit250

Rocha, M. N., Nogueira, P. M., Demicheli, C., De Oliveira, L. G., Da Silva, M. M., Frezard, F., et al. (2013). Cytotoxicity and in vitro antileishmanial activity of antimony (V), Bismuth (V), and Tin (IV) complexes of lapachol. Bioinorg. Chem. Appl. 2013:961783. doi: 10.1155/2013/961783

Rodrigues, P. N., Gomes, S. S., Neves, J. V., Gomes-Pereira, S., CorreiaNeves, M., Nunes-Alves, C., et al. (2011). Mycobacteria-induced anaemia revisited: a molecular approach reveals the involvement of NRAMP1 and lipocalin-2, but not of hepcidin. Immunobiology 216, 1127-1134. doi: 10.1016/j.imbio.2011.04.004

Rodriguez, G. M., and Smith, I. (2006). Identification of an ABC transporter required for iron acquisition and virulence in Mycobacterium tuberculosis. J. Bacteriol. 188, 424-430. doi: 10.1128/JB.188.2.424-430.2006

Rolph, M. S., Raupach, B., Kobernick, H. H., Collins, H. L., Perarnau, B., Lemonnier, F. A., et al. (2001). MHC class Ia-restricted T cells partially account for beta2-microglobulin-dependent resistance to Mycobacterium tuberculosis. Eur. J. Immunol. 31, 1944-1949. doi: 10.1002/1521-4141(200106)31:6<1944::AID-IMMU1944>3.0.CO;2-R

Rowland, J. L., and Niederweis, M. (2012). Resistance mechanisms of Mycobacterium tuberculosis against phagosomal copper overload. Tuberculosis 92, 202-210. doi: 10.1016/j.tube.2011.12.006

Roy, C. N. (2010). Anemia of inflammation. Hematology Am. Soc. Hematol. Educ. Program 2010, 276-280. doi: 10.1182/asheducation-2010.1.276

Sahiratmadja, E., Wieringa, F. T., Van Crevel, R., De Visser, A. W., Adnan, I., Alisjahbana, B., et al. (2007). Iron deficiency and NRAMP1 polymorphisms (INT4, D543N and 3'UTR) do not contribute to severity of anaemia in tuberculosis in the Indonesian population. Br. J. Nutr. 98, 684-690. doi: 10.1017/S0007114507742691

Saiga, H., Nishimura, J., Kuwata, H., Okuyama, M., Matsumoto, S., Sato, S., et al. (2008). Lipocalin 2-dependent inhibition of mycobacterial growth in alveolar epithelium. J. Immunol. 181, 8521-8527.

Sanchez-Robert, E., Altet, L., Utzet-Sadurni, M., Giger, U., Sanchez, A., and Francino, O. (2008). Slc11al (formerly Nramp1) and susceptibility to canine visceral leishmaniasis. Vet. Res. 39, 36. doi: 10.1051/vetres:2008013

Schaible, U. E., Collins, H. L., Priem, F., and Kaufmann, S. H. (2002). Correction of the iron overload defect in beta-2-microglobulin knockout mice by lactoferrin abolishes their increased susceptibility to tuberculosis. J. Exp. Med. 196, 1507-1513. doi: 10.1084/jem.20020897

Schaible, U. E., and Kaufmann, S. H. (2004). Iron and microbial infection. Nat. Rev. Microbiol. 2, 946-953. doi: 10.1038/nrmicro1046

Schubert, T. E., Bosserhoff, A. K., Peyssonaux, C., Echtenacher, B., Knutson, M., Hofstadter, F., et al. (2012). Hypoferraemia during the early inflammatory response is dependent on tumour necrosis factor activity in a murine model of protracted peritonitis. Mol. Med. Rep. 6, 838-842. doi: 10.3892/mmr.2012.1004

Searle, S., Bright, N. A., Roach, T. I., Atkinson, P. G., Barton, C. H., Meloen, R. H., et al. (1998). Localisation of Nrampl in macrophages: modulation with activation and infection. J. Cell Sci. 111(Pt 19), 2855-2866.

Segal, B. H., Doherty, T. M., Wynn, T. A., Cheever, A. W., Sher, A., and Holland, S. M. (1999). The p47(phox-/-) mouse model of chronic granulomatous disease has normal granuloma formation and cytokine responses to Mycobacterium avium and Schistosoma mansoni eggs. Infect. Immun. 67, 1659-1665.

Segovia, M., Navarro, A., and Artero, J. M. (1989). The effect of liposomeentrapped desferrioxamine on Leishmania donovani in vitro. Ann. Trop. Med. Parasitol. 83, 357-360.

Silva-Gomes, S., Appelberg, R., Larsen, R., Soares, M. P., and Gomes, M. S. (2013a). Heme catabolism by heme oxygenase-1 confers host resistance to Mycobacterium infection. Infect. Immun. 81, 2536-2545. doi: 10.1128/IAI.00251-13

Silva-Gomes, S., Bouton, C., Silva, T., Santambrogio, P., Rodrigues, P., Appelberg, R., et al. (2013b). Mycobacterium avium infection induces H-Ferritin expression in mouse primary macrophages by activating Toll-like receptor 2. PLoS ONE e82874. doi: 10.1371/journal.pone.0082874

Singh, N., Bajpai, S., Kumar, V., Gour, J. K., and Singh, R. K. (2013). Identification and functional characterization of Leishmania donovani secretory peroxidase: delineating its role in NRAMP1 regulation. PLoS ONE 8:e53442. doi: 10.1371/journal.pone.0053442

Soe-Lin, S., Apte, S. S., Andriopoulos, B. Jr., Andrews, M. C., Schranzhofer, M., Kahawita, T., et al. (2009). Nrampl promotes efficient macrophage recycling of iron following erythrophagocytosis in vivo. Proc. Natl. Acad. Sci. U.S.A. 106, 5960-5965. doi: 10.1073/pnas.0900808106

Soo, S. S., Villarreal-Ramos, B., Anjam Khan, C. M., Hormaeche, C. E., and Blackwell, J. M. (1998). Genetic control of immune response to recombinant antigens carried by an attenuated Salmonella typhimurium vaccine strain: Nramp1 influences T-helper subset responses and protection against leishmanial challenge. Infect. Immun. 66, 1910-1917.

Soteriadou, K., Papavassiliou, P., Voyiatzaki, C., and Boelaert, J. (1995). Effect of iron chelation on the in-vitro growth of Leishmania promastigotes. J. Antimicrob. Chemother. 35, 23-29. doi: 10.1093/jac/35.1.23

Sow, F. B., Florence, W. C., Satoskar, A. R., Schlesinger, L. S., Zwilling, B. S., and Lafuse, W. P. (2007). Expression and localization of hepcidin in macrophages: a role in host defense against tuberculosis. J. Leukoc. Biol. 82, 934-945. doi: $10.1189 /$ jlb.0407216

Sutak, R., Lesuisse, E., Tachezy, J., and Richardson, D. R. (2008). Crusade for iron: iron uptake in unicellular eukaryotes and its significance for virulence. Trends Microbiol. 16, 261-268. doi: 10.1016/j.tim.2008.03.005

Taylor, M. C., and Kelly, J. M. (2010). Iron metabolism in trypanosomatids, and its crucial role in infection. Parasitology 137, 899-917. doi: $10.1017 /$ S0031182009991880

Trousseau, A. (1872). True, False Chlorosis. Lectures on Clinical Medicine. Philadelphia, PA: Lindsay and Blakiston.

Tullius, M. V., Harmston, C. A., Owens, C. P., Chim, N., Morse, R. P., McMath, L. M., et al. (2011). Discovery and characterization of a unique mycobacterial heme acquisition system. Proc. Natl. Acad. Sci. U.S.A. 108, 5051-5056. doi: 10.1073/pnas. 1009516108

Vale-Costa, S., Gomes-Pereira, S., Teixeira, C. M., Rosa, G., Rodrigues, P. N., Tomas, A., et al. (2013). Iron overload favors the elimination of Leishmania infantum from mouse tissues through interaction with reactive oxygen and nitrogen species. PLoS Negl. Trop. Dis. 7:e2061. doi: 10.1371/journal.pntd.00 02061

Vale-Costa, S., Vale, N., Matos, J., Tomas, A., Moreira, R., Gomes, P., et al. (2012). Peptidomimetic and organometallic derivatives of primaquine active against Leishmania infantum. Antimicrob. Agents Chemother. 56, 5774-5781. doi: 10.1128/AAC.00873-12

Van Zandt, K. E., Sow, F. B., Florence, W. C., Zwilling, B. S., Satoskar, A. R., Schlesinger, L. S., et al. (2008). The iron export protein ferroportin 1 is differentially expressed in mouse macrophage populations and is present in the mycobacterial-containing phagosome. J. Leukoc. Biol. 84, 689-700. doi: 10.1189/jlb.1107781

Vidal, S. M., Malo, D., Vogan, K., Skamene, E., and Gros, P. (1993). Natural resistance to infection with intracellular parasites: isolation of a candidate for Bcg. Cell 73, 469-485. doi: 10.1016/0092-8674(93)90135-D 
Vidal, S., Tremblay, M. L., Govoni, G., Gauthier, S., Sebastiani, G., Malo, D., et al. (1995). The Ity/Lsh/Bcg locus: natural resistance to infection with intracellular parasites is abrogated by disruption of the Nrampl gene. J. Exp. Med. 182, 655-666. doi: 10.1084/jem.182.3.655

Wagner, D., Maser, J., Lai, B., Cai, Z., Barry, C. E. 3rd., Honer Zu Bentrup, K., et al. (2005). Elemental analysis of Mycobacterium avium-, Mycobacterium tuberculosis-, and Mycobacterium smegmatis-containing phagosomes indicates pathogen-induced microenvironments within the host cell's endosomal system. J. Immunol. 174, 1491-1500.

Weinberg, E. D. (2009). Iron availability and infection. Biochim. Biophys. Acta 1790, 600-605. doi: 10.1016/j.bbagen.2008.07.002

Weiss, G. (2009). Iron metabolism in the anemia of chronic disease. Biochim. Biophys. Acta 1790, 682-693. doi: 10.1016/j.bbagen.2008.08.006

Wells, R. M., Jones, C. M., Xi, Z., Speer, A., Danilchanka, O., Doornbos, K. S., et al. (2013). Discovery of a siderophore export system essential for virulence of Mycobacterium tuberculosis. PLoS Pathog. 9:e1003120. doi: 10.1371/journal.ppat. 1003120

Wessling-Resnick, M. (2010). Iron homeostasis and the inflammatory response. Annu. Rev. Nutr. 30, 105-122. doi: 10.1146/annurev.nutr.012809.104804

White, C., Lee, J., Kambe, T., Fritsche, K., and Petris, M. J. (2009). A role for the ATP7A copper-transporting ATPase in macrophage bactericidal activity. J. Biol. Chem. 284, 33949-33956. doi: 10.1074/jbc.M109.070201

White, J. K., Mastroeni, P., Popoff, J. F., Evans, C. A., and Blackwell, J. M. (2005). Slc1la1-mediated resistance to Salmonella enterica serovar Typhimurium and Leishmania donovani infections does not require functional inducible nitric oxide synthase or phagocyte oxidase activity. J. Leukoc. Biol. 77, 311-320. doi: 10.1189/jlb.0904546

White, J. K., Stewart, A., Popoff, J. F., Wilson, S., and Blackwell, J. M. (2004). Incomplete glycosylation and defective intracellular targeting of mutant solute carrier family 11 member 1 (Slc1la1). Biochem. J. 382, 811-819. doi: 10.1042/BJ20040808

Wolschendorf, F., Ackart, D., Shrestha, T. B., Hascall-Dove, L., Nolan, S., Lamichhane, G., et al. (2011). Copper resistance is essential for virulence of
Mycobacterium tuberculosis. Proc. Natl. Acad. Sci. U.S.A. 108, 1621-1626. doi: 10.1073/pnas. 1009261108

Xiong, S., She, H., Takeuchi, H., Han, B., Engelhardt, J. F., Barton, C. H., et al. (2003). Signaling role of intracellular iron in NF-kappaB activation. J. Biol. Chem. 278, 17646-17654. doi: 10.1074/jbc.M210905200

Yang, F., Liu, X. B., Quinones, M., Melby, P. C., Ghio, A., and Haile, D. J. (2002). Regulation of reticuloendothelial iron transporter MTP1 (Slc1la3) by inflammation. J. Biol. Chem. 277, 39786-39791. doi: 10.1074/jbc.M201485200

Zhou, X. Y., Tomatsu, S., Fleming, R. E., Parkkila, S., Waheed, A., Jiang, J., et al. (1998). HFE gene knockout produces mouse model of hereditary hemochromatosis. Proc. Natl. Acad. Sci. U.S.A. 95, 2492-2497. doi: 10.1073/pnas.95. 5.2492

Zwilling, B. S., Kuhn, D. E., Wikoff, L., Brown, D., and Lafuse, W. (1999). Role of iron in Nrampl-mediated inhibition of mycobacterial growth. Infect. Immun. 67, 1386-1392.

Conflict of Interest Statement: The authors declare that the research was conducted in the absence of any commercial or financial relationships that could be construed as a potential conflict of interest.

Received: 29 July 2013; accepted: 21 November 2013; published online: 09 December 2013.

Citation: Silva-Gomes S, Vale-Costa S, Appelberg R and Gomes MS (2013) Iron in intracellular infection: to provide or to deprive? Front. Cell. Infect. Microbiol. 3:96. doi: 10.3389/fcimb.2013.00096

This article was submitted to the journal Frontiers in Cellular and Infection Microbiology.

Copyright (c) 2013 Silva-Gomes, Vale-Costa, Appelberg and Gomes. This is an openaccess article distributed under the terms of the Creative Commons Attribution License (CC BY). The use, distribution or reproduction in other forums is permitted, provided the original author(s) or licensor are credited and that the original publication in this journal is cited, in accordance with accepted academic practice. No use, distribution or reproduction is permitted which does not comply with these terms. 